\title{
Desafíos gerenciales de los sistemas de salud en Colombia y Venezuela
}

\author{
Teresa Gamboa C.* y Elba Lucía Rangel G.**
}

\section{Resumen}

Se estudia la organización de los sistemas de salud, los factores politicos y sociales que los determinan o condicionan y los desafios planteados a la gerencia de los respectivos paises para optimizar los servicios, especialmente en términos de cobertura y calidad en el marco de las nuevas condiciones económicas y políticas. En Colombia, se diseña un servicio altamente modernizado, donde se diluyen los conceptos de lo público y lo privado; se fundamenta en el financiamiento a la demanda según una unidad de pago per cápita y en la competitividad basada en la eficiencia con riesgo de afectar la calidad del servicio; tiende a universalizar la cobertura, lo cual sólo ha logrado en un $50 \%$ después de tres años de su instauración; y está condicionado por la demanda de servicios de urgencia y quirúrgicos a causa de la violencia de diversos signos. En Venezuela, por el contrario, los servicios públicos de salud han colapsado, predominando la anarquía y la insuficiencia, a pesar del volumen del gasto público y la infraestructura disponible; la descentralización ha enfrentado obstáculos legales y prácticos que aún no ha podido superar; se manejan propuestas todavía no suficientemente estructuradas para reorganizar el sistema tomando ideas aisladas de los modelos colombiano y chileno, pero manteniendo la diferenciación entre los tres modelos hoy existentes: el público de atención abierta, el mixto restringido y el privado; existen limitaciones legales y prácticas para la reorganización de la salud en Venezuela.

Palabras claves: Sistemas de salud, Colombia, Venezuela, Salud Pública, Salud Privada, Reestructuración de la Salud.

\section{Recibido: 16-07-96 - Aceptado: 09-09-96}

* Contador Público, Magister en Evaluación de Empresas Públicas, Profesora Titular e Investigadora del Centro de Estudios de la Empresa, Facultad de Ciencias Económicas y Sociales, Universidad del Zulia.

* Estudiante, $11^{\text {t }}$ Semestre, Facultad de Medicina, Universidad del Zulia 


\section{Managerial Challenges Posed by Colombia and Venezuelan Health Systems}

\section{Abstract}

In this paper, the organization of the health systems, the political and social factors which condition or determine said systems, and the challenges which each country faces in the optimization of its respective system are studied, especially in terms of the coverage and quality of the service in the context of the new economic and political conditions. In Colombia, a new and highly modernized system is being designed, where the concepts of public and private are diluted. This new system is based on financial support of demand in terms of a per capita unit of payment and on competitivity in terms of efficiency with the risk of affecting the quality of service; the coverage tends to be universal but after three years in operation, it has only reached $50 \%$ of the population and it is conditioned by the demand for surgical and emergency services due to the violence of diverse signs. In Venezuela, on the contrary, public health services have colapsed, anarchy and insufficiency predominate in spite of the high level of public expenditure and the availability of infrastructure; decentralization has encountered legal and practical obstacles which have not been overcome; several proposals have been offered, without sufficient elaboration, towards a reorganization of the system taking isolated ideas from the colombian and chilean systems, but retaining the differences inherent in the three systems (i.e. free public service; restricted semi-private facilities and private service). There are legal and practical limitations which inhibit the reorganization of the health system in Venezuela.

Key words: Health systems, Public and private health services, Venezuelan health system, Colombian health system, reorganzation of health services.

\section{Introducción}

Los paises con una geografía común comparten inevitablemente raíces históricas. En nuestro caso, Colombia y Venezuela lucharon juntas por la independencia de España, fueron regidas por el mismo gobierno en los primeros años de la República; en algunas épocas se han creado circuitos económicos muy fuertes, que han producido prácticamente sub-regiones bien caracterizadas; los procesos migratorios han llevado sus habitantes de uno a otro país, por razones personales, económicas o polfticas, como ocurrió con el Dr. José Urquinaona Bracho, fundador a mediados del siglo $\mathrm{XIX}$ de dos hospitales en Maracaibo, quien luego fue administrador del Hospital de Cúcuta. (Ramírez Calderón, 1979, 57-59).

A pesar de los nexos y similitudes, cada pais desarrolla su propia identidad y construye su propio destino, aun cuando la cercanía genere consecuencias que no implican necesariamente el "destino manifiesto de hermanas repúblicas" quebrado muchas veces por el nacionalismo 
exacerbado y la xenofobia alimentados de acuerdo a las circunstancias. (Escalante, 1996a).

Colombia y Venezuela, han visto incrementar en las dos últimas décadas enfermedades de fácil transmisión, que se creian erradicadas, tales como la malaria, el dengue, la fiebre amarilla, enfermedad de Chagas, encefalitis equina y el cólera; están condicionadas por factores socio-culturales vinculados al desarrollo y a la situación económica que afecta a la mayoría de la población de América Latina, (Maingón, 1991,93 ) aunque algunos indicadores sugieren que la situación de Venezuela es más grave, puesto que está viviendo una grave crisis socioeconómica, mientras en Colombia se aprecian sintomas de crecimiento económico a pesar de la situación política. Colombia padece una violencia crónica, que genera problemas particulares de salud; coletazos de esta violencia alcanzan a Venezuela, especialmente en las fronteras; además la crisis ha desatado el auge de la delincuencia, con asaltos, secuestros y violaciones.

En un sentido general, la tendencia probable en América Latina es hacia la privatización de los servicios de salud, con incremento de las pólizas de seguros de hospitalización, cirugía y maternidad y otras formas de medicina pre-pagada y con la creación de sistemas privados de seguridad social en salud en países como Chile, Costa Rica, Brasil (Maingón, $1991,93)$ y más recientemente en Colombia, logrando una relativa eficacia en su funcionamiento. Entre tanto, Venezuela vive el colapso de los servicios de salud, evidenciando altos grados de incapaci- dad para reorganizar el sistema, que luce ingobernable.

Este informe intentará establecer los rasgos generales que determinan la situación de los servicios de salud en los dos países y caracterizará los respectivos sistemas de atención en salud, de modo que puedan evidenciarse sus profundas diferencias y algunas similitudes, así como identificar los retos gerenciales de ellos tienen planteados.

\section{Violencia y Salud en Colombia}

Históricamente Colombia es un pais caracterizado por una sociedad conservadora, cargada de privilegios y desigualdades, en la cual la violencia ha sido herramienta tradicional de la confrontación política y de la lucha por la conquista de reivindicaciones sociales. Desde 1947 , con diversas motivaciones y métodos, Colombia soporta una violencia que ha causado mas de $\mathbf{5 0 0}$ mil muertos. Esto reviste mayor relevancia si se considera que entre los diez factores con mayor incidencia en la mortalidad en el mundo, no figura la violencia. (OMS). Ejercida por múltiples actores entre los que se cuentan las fuerzas armadas y los cuerpos de seguridad del Estado, las guerrillas, y más recientemente los grupos paramilitares y los traficantes de drogas, la violencia es característica que Colombia comparte con pocos países latinoamericanos. La mayoría de las víctimas provienen de los sectores populares, particularmente líderes de sus organizaciones representativas, lo cual ha favorecido su debilitamiento y desintegración. 
(Apuleyo Mendoza, 1990; Bejarano, 1993; Castillo, 1988; Diaz Callejas, 1992; Salazar, 1990)

En Bogotá los accidentes y ataques con armas de fuego y explosivos $y$ en menor grado con instrumentos cortantes y punzantes, se convirtieron desde mediados de la década del 70 en los factores predominantes de mortalidad y morbilidad, especialmente en el sexo masculino y con mayor fuerza en el grupo etario de 15 a 44 años. (Restrepo, 1980). Si bien la violencia presenta diferentes grados según la zona y la coyuntura socioeconómica y política, es indudable que la situación de la capital es un reflejo del país, aunque la ciudad más afectada es Medellín.

La violencia determina la importancia y el carácter de las unidades de atención de urgencia y convierte a traumatología no sólo en una especialidad vital, sino en una razón para el desplazamiento de otras. Esto, junto con los accidentes de tránsito, conduce a que la reorganización del sistema de salud de conformidad con la Ley 10 de 1990 , haya establecido decretos específicos sobre el seguro obligatorio de daños a personas causados por accidentes, conjuntamente con disposiciones sobre el manejo de los recursos para el mejoramiento de los servicios de atención médica de urgencias y medidas para la atención hospitalaria a las víctimas de atentados terroristas. (Ministerio de Salud, 1991). Igualmente es comprensible que al producirse la reorganización total del sistema de seguridad social en salud según la Ley 100 de 1993, se haya establecido que la atención inicial de urgencias debe ser prestada en forma obligatoria por todas las entidades públicas o privadas que ofrecen servicios de salud, a todas las personas, independientemente de la capacidad de pago, sin contrato ni orden previa. (Legis, 1996)

En cuanto a los efectos de la violencia en el funcionamiento do los hospitales, vale la pena destacar dos experiencias contrapuestas en Cúcuta y Bucaramanga. En esta última ciudad la construcción de un moderno hospital pretendió acabar con el existente hasta el momento, cuestión que fue objetada por su personal; especialmente los médicos defendieron la institución y lograron diversas fuentes de financiamiento para mantenerlo como hospital diurno, destinado básicamente a cirugias de bajo riesgo, que no requieren hospitalización bien sea por su naturaleza o por las ventajas que ofrecen las nuevas tecnologías quirúrgicas.

En Cúcuta se decidió todo lo contrario. El nuevo Hospital Erasmo Meoz decretó la muerte del bicentenario Hospital de San Juan de Dios, estrechamente ligado a la historia de la ciudad; fue abierto el 19-11-87, con III nivel de atención y séptimo en complejidad debido a su tecnología y organización; a pesar de su capacidad (520 camas y todos los servicios esenciales), sufre los embates de la demanda de servicios a causa de la violencia, agravados por la decisión de cerrar el Hospital San Juan de Dios, el cual pudo tener el destino de su homólogo en Bucaramanga. Los quirófanos están permanentemente congestionados y las cirugías programadas son continuamente diferidas, en detrimento de la salud de la población. (HEM, 1988; Cáceres, 1996) 


\section{Modernización del Sistema Colombiano de Salud}

La reforma del estado colombiano está vinculada al proceso político y social, pero indudablemente responde también al modelo económico que se trata de impulsar. En el caso de la modernización del sistema de seguridad social en salud se aprecian claramente las diferentes implicaciones; sus características responden a las demandas sociales marcadas por el signo de la violencia, a la ampliación de la participación política y a la instauración de la economía de mercado reduciendo al mínimo la intervención estatal directa, rasgos propios del Estado neoliberal. Tal como sostiene Ochoa Henriquez (1996) las características que toma la administración pública, es decir los procesos de decisión y ejecución en el poder ejecutivo, están estrechamente ligados a las necesidades del modelo económico que promueve el Estado, en cuyo marco se inscriben los requerimientos de la democracia.

Ahora bien, el colombiano nunca fue un Estado fuertemente interventor; no solo es pequeño, sino que tampoco ha satisfecho jamás las necesidades básicas de una parte significativa de la población, por lo que la reforma de la administración pública no significa el desmantelamiento de la estructura de un Estado de Bienestar que nunca llegó a configurarse. Lo paradójico es que se adelante la reforma del Estado cuando la Asamblea Constituyente de 1991 lo señala como el responsable del bienestar de sus ciudadanos. (Bejarano, 1993, 53).

Durante mas de un siglo los desti- nos de Colombia fueron regidos por la Constitución de 1886, la cual institucionalizó una democracia centralista, autoritaria y restringida que funcionó casi siempre bajo estado de sitio - restricción de las garantfas constitucionales -, lo cual no obsta para que sea considerado como el país latinoamericano con mayor trayectoria democrático - representativa. Las Constituciones del siglo XIX fueron la culminación de grandes confrontaciones bélicas, por lo cual su aprobación careció de participación popular; solamente en 1991 el pueblo colombiano pudo nombrar los miembros de la Constituyente en elecciones directas, imponiendo una composición que rompió la tradición elitista al elegir diversos tipos de profesionales, ex - guerrilleros, líderes sindicales, predicadores evangélicos, indígenas, etc. de las mas variadas condiciones sociales. Lo anterior está directamente ligado al proceso de pacificación en el cual participaron algunas organizaciones guerrilleras. Haciendo uso de las facultades especiales que le confiere el estado de sitio, el Ejecutivo garantizó posiciones en la Asamblea Constituyente al Ejército Popular de Liberación (EPL), al Partido Revolucionario de los Trabajadores (PRT) y a la guerrilla indígena Quintín Lame, sujeto a que abandonaran las armas. Por su parte, el M19 se sometió al debate electoral abierto, obteniendo 19 de los 70 escaños. En general los resultados quebraron el bipartidismo tradicional liberal conservador. (Díaz Callejas, 1992, 29).

Entre los principales componentes de la Constitución de 1991, en la cual prevaleció el consenso, se consagran claramente derechos sociales como los 
de seguridad social, salud y educación; se garantiza a todo niño menor de un año atención médica gratuita en las instituciones de salud que tengan algún aporte del Estado; se establece el derecho a la vivienda, al bienestar de la familia, la recreación y el medio ambiente, así como el derecho de huelga y contratación colectiva. Por otra parte, se definen mecanismos de participación popular y la democratización de la propiedad como elemento primordial en la enajenación del Estado; se establece la responsabilidad del Estado ante los ciudadanos; las acciones populares para la protección de los derechos e intereses colectivos $y$, finalmente, se instituye la acción de tutela similar al derecho de amparo constitucional en Venezuela, pero más eficaz - para reclamar el cumplimiento inmediato de las garantías constitucionales.

La instrumentación de los derechos en materia de seguridad social se inicia con la entrada en vigencia de la Ley 100 de 1993, reglamentada a su vez con la expedición de numerosos decretos. Su aplicación ha generado grandes expectativas, a la vez que ha suscitado conflictos entre los diversos sectores afectados. Sin embargo, los primeros pasos hacia la modernización del Estado se dieron previamente, durante el gobierno de Gaviria, quien enfatizó las privatizaciones y la desregulación de los mercados laboral, financiero y cambiario, características del estado neoliberal que aspira transformar su administración burocrático - populista en tecnocrática.

El Gobierno de Gaviria crea las bases de la modernización, al reorganizar el sistema nacional de salud con las si- guientes disposiciones, entre otras: a) descentralización hacia los municipios de la dirección y prestación de servicios de salud del primer nivel de atención y hacia los departamentos los servicios de segundo y tercer nivel que comprenden los hospitales regionales, universitarios y especializados; b) organización de modalidades de participación comunitaria en el diagnóstico, formulación y elaboración de planes, programas y proyectos, toma de decisiones y administración; c) obligatoriedad de establecer sistemas de contabilidad de costos y control de gestión en las entidades oficiales de salud; d) previsión de un sistema para la fijación y control de tarifas por la prestación de servicios; e) definición de responsabilidades especiales sobre los serviclos de urgencias; $y$ f) regulación de los servicios de medicina pre-pagada. (Ministerio de Salud, 1991).

Las medidas descentralizadoras iban acompañadas de disposiciones relativas a la posibilidad de cierre definitivo de las instituciones hospitalarias cuya eficlencia no pudiera garantizarse; las reformas decretadas implicaban la reducción del empleo en el sector público, que en el caso colombiano nunca ha sido relevante, pues sólo absorbe el $9 \%$ de la fuerza de trabajo activa.

El presidente Gaviria empieza a introducir las propuestas en salud, en agosto de 1992; siendo ministro de salud Antonio Navarro Wolf, dirigente de la Alianza Democrática M-19, el Ejecutivo planteó la privatización del Instituto de Seguros Sociales y la aplicación del modelo chileno de seguridad social; esto fue rechazado por el M-19 y provocó su salida del go- 
bierno, asi como la resistencia del personal y de los proveedores, aunque existia relativo consenso respecto a la necesidad de transformar las instituciones de salud, por costosas, ineficientes, burocratizadas, desconocedoras de las necesidades de los usuarios y generadoras de corrupción. (Bejarano, 1993, 56).

\section{Caracteristicas Generales del Sistema Colombiano de Salud}

La Ley 100 de 1993 profundiza radicalmente el proceso de modernización de los sistemas de seguridad social. Básicamente podria pensarse que se trata de una adaptación del sistema Kaiser o de medicina integral pre-pagada, el cual fue establecido originalmente durante la depresión de los años 30 en California, Estados Unidos, por un joven cirujano, el Dr. Sidney Garfield y generalizado años después con apoyo del industrial Henry Kaiser, quien lo organizó para el personal de sus empresas en 24 países; Kaiser se convirtió luego en empresario de la salud. (Arias, 1980, 89-91). Recientemente, la esposa del presidente Clinton intentó infructuosamente promover la idea de universalizar la medicina pre-pagada en Estados Unidos y vincularla a la política social del Estado.

Los sistemas de medicina integral pre-pagada, a diferencia de la práctica privada común de carácter individual, funcionan con grupos de población afiliados al sistema a través de la contratación de servicios a cambio del pago de una cantidad fija mensual; se fundamentan en los principios de probabilidad y distribución del riesgo propios de las empresas de seguros, ofreciendo a una población amplia y definida, durante un período de tiempo, diversos servicios de salud.

La medicina integral pre-pagada crea la posibilidad de seguimiento de las condiciones de salud del afiliado y su grupo familiar, porque establece una relación mas permanente de los usuarios con el médico y la institución de asistencia médico - hospitalaria. En principio, tiene la obligación de mantener a su población afiliada en el mejor estado de salud posible, to cual redunda en reducción de los costos de la medicina curativa; para lograr la prevención utiliza los principios de una medicina positiva y activa, que busca al paciente y to hace participar en el proceso de atención de la salud, en un esfuerzo por evitar la enfermedad o al menos diagnosticarla precozmente. No se contenta con responder pasivamente a la demanda de servicios, sino que induce la propia demanda, cuando la intervención del sistema es más efectiva y de menor costo. (Arias, 1980, 93).

Sin embargo, el sistema privado de salud sin intervención estatal tiene limitaciones:

Si bien el modelo de mercado para los seguros de salud ha tenido un gran desarrollo en Estados Unidos, aunque produciendo un desbordamiento de los costos y sin lograr la cobertura universal, es en el modelo chileno donde pueden observarse mejor sus efectos negativos, entre los cuales se pueden identificar al menos cuatro fenómenos de exclusión o de selección adversa de los grupos sociales que más necesitan la atención en salud: exclusión de los 
pobres, las maternas, los ancianos y los enfermos costosos ... La chileniza* ción como alternativa neoliberal a la seguridad social clásica, asegura el éxito empresarial de las entidades privadas de previsión social ... el sistema chileno es muy bueno cuando se es varón, joven, adinerado y no se padece ninguna enfermedad grave. (Jaramillo, $1994,27,31)$

La legislación colombiana, resultado de un intenso debate, concilia posiciones de los estatistas y de los privatizadores, sin asumir el modelo neoliberal chileno; institucionaliza y universaliza la medicina integral pre-pagada, con lo cual privatiza factual y legalmente la prestación de los servicios de salud, ya que abre espacios a la participación privada en áreas que antes estaban reservadas al sector público pero refuerza la acción reguladora y de control del Estado. Además, impone la tesis de lo público en términos de la financiación colectiva del servlcio, frente a la concepción basada en el funcionamiento, en tanto el bien sea producido o el servicio prestado por una institución de carácter gubernamental. (Donahue, 1991,22).

Coincidimos con Jaramillo (1994,46-53) en cuanto que el modelo colombiano, aunque incluye elementos desarrollados en Europa, E.U. y Chile, no puede decirse que sea copia de lo existente en otro país; a diferencia del enfoque neoliberal, no es un sistema de precios, sino un sistema contributivo proporcional al ingreso individual, con beneficios acordes a las necesidades; es solidario con subsidios cruzados, integral con co- bertura familiar, cuenta con mecanismos para impedir las exclusiones y además, posee instrumentos bien definidos de intervención estatal. A su vez difiere de la seguridad social clásica por cuanto rompe con el principio de unidad, entendida como monopolio de los sistemas de seguro y de prestación de los servicios; crea mecanismos para hacer operativo el principio de universalidad y se basa en la descentralización institucional más que en la territorial.

\section{Cobertura de los Servicios}

La sociedad colombiana, además de las restricciones a la participación politica, ha estado marcada por desigualdades sociales extremas; los niveles de concentración del ingreso son muy altos, ya que el $50 \%$ de la población más pobre obtiene el $17.6 \%$ del ingreso total mientras el $20 \%$ más rico controla casi el $55 \%$; en 1990 el $49 \%$ de la población se encontraba por debajo de la línea de pobreza, mientras casi el $37 \%$ vivía en pobreza crítica, sin posibilidad de satisfacción de las necesidades básicas. (Bejarano, 1993, 60). Por otra parte, el Instituto de Seguros Sociales solo atendía el $50 \%$ de los asalariados, equivalente al $16 \%$ de la población total; sus funciones se complementaban por múltiples servicios de salud institucionales, además de las Cajas de Previsión y las de Compensación Familiar (Jaramillo, 1994,33). Es en estas condiciones que la Ley 100 plantea el principio de universalidad de la atención de la salud.

El sistema colombiano de seguridad social en salud (CRC, 1993; Le- 
gis, 1996) ${ }^{1}$ tiene como objetivo regular el servicio público esencial de salud y crear condiciones de acceso de la población a todos los niveles de atención para la pro. moción, protección y recuperación de la salud. Se propone proveer gradualmente igual calidad de salud a todos los habitantes, independientemente de su capacidad de pago, por lo cual subsidia y controla los servicios para la población mas pobre y vulnerable.

La Ley establece la afillación obligatoria al sistema, bajo dos modalidades: un régimen contributivo y otro subsidiado. La afiliación colectiva es responsabilidad de los empleadores y de los gremios o las asociaciones por asentamiento geográfico; la afiliación es individual para los trabajadores independientes con capacidad de pago. El valor de la cotización en el régimen contributivo, con cobertura familiar, es de un $12 \%$ del salario, distribuido asi: $4 \%$ el trabajador y $8 \%$ el empleador. La base de cotización tiene como límite inferior un salario mínimo y como tope máximo 20 salarios minimos legales vigentes. El trabajador independiente debe pagar el porcentaje total.

En Chile funciona un sistema aparentemente similar, que se financia con un aporte exclusivo de los trabajadores, cuyo mínimo equivale al $7 \%$; dependiendo del paquete que elija según la capacidad adquisitiva del usuario, entre cerca de cinco mil planes diferentes, se establece el porcentaje que deberá pagar; esto ha generado un sistema diferenciado para ricos y pobres, el primero en manos de empresas privadas exitosas y el segundo en las entidades públicas, por lo general en situación de quiebra (Pardo, 1994,56; Jaramillo, 1994,22,46)

Como mecanismo de control sobre los empleadores, la Ley 100 de 1993 les impone a éstos la obligación de cubrir en su totalidad los gastos por atención de accidentes de trabajo, riesgos y eventualidades por enfermedad general, maternidad y enfermedad profesional, en caso de que el patrono no haya realizado la inscripción del trabajador a no cancele oportunamente las cotizaciones en la entidad correspondiente. Por otra parte, para controlar la afiliación, el Gobierno Nacional exige la presentación del carnet respectivo en diversas ocasiones, tales como la celebración de contratos con el Estado y el otorgamiento de licencias de operación de transporte o de construcción.

La afiliación es obligatoria, pero los beneficiarios pueden elegir libremente tanto la entidad promotora de salud (EPS) a la cual cotizarán, como la institución prestadora de servicios (IPS) a la cual los demandarán, pudiendo cambiarse solo una vez cada año. El sistema prohíbe expresamente la realización de convenios que restrinjan la libertad de elección, la cual en todo caso tiene un límite natural establecido por la relación entre la EPS elegida y las IPS con las cuales ésta mantiene contrato de servicios.

Los afiliados contributivos están amparados en cuanto a: riesgos no profesionales por enfermedad general, macamente es tomada de Legis y de la Ley 100 de 1993. 
ternidad, accidentes de trabajo y enfermedad profesional; subsidio económico a la vejez y al desempleo o paro forzoso. La prestación de los servicios se organiza a través de los siguientes planes: atención báslca, dirigido a la colectividad en forma gratuita y obligatoria, bajo la responsabilidad directa del Ministerio de Salud, relativo a información y educación en salud; saneamiento ambiental, complementación nutricional, planificación familiar, prevención primaria y diagnóstico precoz sobre las personas respecto a patologias y riesgos con altas manifestaciones o sobre las comunidades en el caso de endemias y epidemias; plan obllgatorio de salud, administrado por las empresas promotoras de salud, relativo a la atención en salud e Indemnizaciones económicas. Los afiliados contributivos pueden igualmente convenir con las empresas promotoras de salud o con otras empresas de medicina pre-pagada, planes complementarios, que garanticen la atención en caso de requerir procedimientos o intervenciones no incluidas en el plan obligatorio de salud o que requieran condiciones de hotelería, tecnología u otra característica adicional . El sistema garantiza a todos los habitantes del territorio colombiano la atención en saIud derivada de accldentes de tránsito, con cargo a la aseguradora del vehículo causante del siniestro; además, garantiza a las Instituciones Prestadoras de Servicios, el pago por la atención de las víctimas de catástrofes naturales, de actos terroristas o de otros eventos autorizados por el Estado.

El régimen subsidiado - parcial o total - pretende asegurar el ingreso al sistema de los sectores mas pobres y vulnerables de la población colomblana; se financia con recursos fiscales o contribuciones solidarias. La Ley establece las fuentes de recursos fiscales para el régimen subsidiado. Pueden afiliarse los trabajadores independientes cuyos ingresos mensuales familiares sean inferiores a dos salarios mínimos legales; las personas sin capacidad de pago y aquellos miembros de la población mas vuinerables por su situación de salud, que se definan como prioritarios, especialmente los siguientes: las mujeres durante el embarazo, parto, post parto y lactancia; los niños menores de un año; las madres comunitarias - responsables de grupos de niños en hogares de cuidado diario - y las madres cabeza de familia. Esto tiende a garantizar la reproducción de la fuerza laboral, dado que la pirámide poblacional está siendo afectada seriamente por las muertes violentas, concentradas básicamente en la edad potencialmente activa.

Para que el principio de universalidad se logre, es decir, que todos los habitantes del territorio colombiano tengan acceso a los servicios de salud en un plazo máximo de cinco años, como está previsto, se requiere que se afilien 18 millones de colom. bianos que aún están fuera del sistema a mediados de 1996 (aproximadamente ol $50 \%$ de la población). Ellos son tanto trabajadores independientes que tendrán que ingresar al régimen contributivo, como aquellas personas que todavía faltan por entrar al régimen subsidiado: los colombianos más pobres. El límite de pobreza fijado para acceder al régimen subsidiado es demasiado estricto y debe ser modificado, según el representante de los profesionales 
de la salud al Consejo Nacional de Seguridad Social. (Ospina Hurtado, 1996).

\section{Claves Administrativas del Sistema de Seguridad Social en Salud}

Sin asumir plenamente el modelo neoliberal, el Estado colombiano ha diseñado un sistema administrativo basado en la descentralización institucional mas que en la territorial y en la delegación de muchas funciones al sector privado. Para su ejecución, la Ley 100 de 1993 define la separación entre las entidades responsables del aseguramiento y financiación, respecto a las prestadoras de los servicios de salud, asi como mecanismos claros de intervención estatal; establece cuatro tipos de organismos públicos o privados: las entidades promotoras de salud (EPS), las instituciones prestadoras de servicios (IPS), las empresas solidarias de salud (ESS) y los organismos estatales de dirección, vigilancia y control, como son: Consejo Nacional, Superintendencia Nacional y Fondo de Solidaridad y Garantia (Ver gráfico 1). Es la sustitución del sistema piramidal burocrático y rígido, por uno de "redes de instituciones interrelacionadas, que maximicen la coordinación, la obtención de economías de escala y la explotación de sinergias", esto es, el concurso activo y concertado de diversas instituciones en función de un objetivo. (Klisberg, 1994)

Las Empresas Promotoras de Salud EPS, tienen a su cargo: a) la afiliación y carnetización de personas con diferentes tipos de riesgos de salud, del régimen contributivo y del subsidiado; b) la recaudación de las cotizaciones; c) la organización de la prestación de los servicios de salud correspondientes al plan obligatorio de salud (POS) para todos sus afiliados directamente o por la contratación con instituciones Prestadoras de Servicios, con profesionales independientes o con grupos de práctica privada debidamente constituidos; y d) facilitar a las IPS la compensación con el Fondo de Solidaridad y Garantía.

Las EPS, organizaciones similares al Seguro Social, pueden ser públicas, privadas o mixtas; deben disponer de una organización administrativa y financiera que garantice la base de datos y capacidad técnica indispensables y la evaluación sistemática de los servicios de salud ofrecidos a sus afiliados. Deben mantener un número mínimo de 50.000 de afiliados que asegure niveles viables de operación y supervivencia aprovechando las economías de escala y un número máximo que garantice la competitividad; un capital o fondo social no inferior a 10.000 salarios mínimos legales mensuales; no menos del $5 \%$ de los afiliados deben ser mayores de 60 años y al menos el $20 \%$ mujeres en edad fértil.

Se incluyen entre las EPS el Instituto de Seguros Sociales, las entidades de previsión y seguridad social del sector público (a las cuales dieron un plazo para pasar del acceso restringido al abierto), las instituciones de medicina pre-pagada o de seguros de salud, los servicios de salud empresariales o institucionales y cualquier organización que se constituya y sea autorizada como tal por la Superintendencia Nacional de Salud. Las compañías de seguros están habilitadas para 
convertirse en EPS; aquellas con experiencia en seguros de hospitalización, cirugía y maternidad tienen ventaja evidente en la competencia con otras EPS.

Las EPS constituyen el eje del sistema de seguridad social en salud, al actuar como organismos de intermediación entre los afiliados y sus empleadores respecto a las instituciones prestadoras de servicios, asi como entre éstas y el Fondo de Solidaridad y Garantía del Estado; a través de dicho Fondo, el Estado reconoce a las entidades promotoras de salud (EPS), por organizar y garantizar la prestación de los servicios del plan de salud obligatorio (POS) a los afiliados, un valor per cápita o unidad de pago por capitación, establecida por el Consejo Nacional de Seguridad Social, de acuerdo al perfil epidemiológico de la población relevante, a los riesgos cubiertos y a los costos de prestación del servicio en condiciones medias de calidad, tecnologia y hoteleria, según los estudios técnicos del Ministerio de Salud. De esta forma se "mantiene el sistema de compensación entre las EPS, pues cada una recoge las cotizaciones de sus afiliados, pero deduce sólo el costo estándar de la atención (UPC) por cada beneficiario bajo su responsabilidad, de tal forma que las EPS superavitarias podrán compensar a las deficitarias" lo cual constituye la base de la solidaridad; con el valor de la UPC "que ascendería en 1995 en promedio a $\$ 150$ anuales, la EPS no sólo deberá sufragar los gastos incurridos en la atención de la enfermedad y la maternidad, sino en general los gastos de la estrategia de protección de la salud y la administración del sistema de aseguramiento, pero sin superar el nivel de la UPC a riesgo de incurrir en quiebra. Sin embargo, es posible que la opción de encontrar rentabilidad descanse básicamente en los planes complementarios" (Jaramillo, 1994, 32, 45); la recaudación por cada afiliado que devenga salario mínimo apenas sobrepasa los $\$ 170$ anuales debiendo garantizar el servicio al grupo familiar.

El Fondo de Solidaridad y Garantía está adscrito al Ministerio de Salud y se maneja por encargo fiduciario, sin personalidad jurídica ni personal propio. Por razones operativas, cada entidad territorial debe organizar un fondo local o regio. nal de salud al cual se destinan los recursos asignados o recaudados para financiar el subsidio a la demanda en servicios de salud. El Fondo tiene por objeto fundamental facilitar la ampliación de la cobertura en salud, garantizar la compensación entre personas con distintos ingresos y/o riesgos y cubrir los riesgos por catástrofes, terrorismo y accidentes de tránsito.

La recaudación de las cotizacio. nes es realizada en principio por los empleadores o por las empresas solidarias de salud y pagada mensualmente a las EPS; éstas actúan por delegación del Fondo de Solidaridad y Garantia, al cual deben rendir cuenta el primer día hábil siguiente a la fecha límite establecida para el pago de las cotizaciones por parte de los empleadores y de los contribuyentes individuales. Si el monto de las contribuciones recaudadas es superior a la unidad de pago por capitación multiplicada por el número de los beneficiarios atendidos por la EPS, ésta depositará la diferencia a favor del Fondo; en caso 
contrario el Fondo de Solidaridad y Garantía deberá cancelar la diferencia a favor de la EPS el mismo día que ésta lo reporte.

La inclusión de las empresas solidarias de salud (ESS) constituye un mecanismo para facilitar el funcionamiento del régimen subsidiado, aliviando la carga administrativa de las EPS. Consiste en la organización de la comunidad para contratar servicios de salud subsidiados por el Estado, cuyos miembros se vinculan a ella mediante una cuota de afiliación o por la compra de una acción o participación. Las ESS pueden partir de formas de organización popular ya existentes, pero esta propuesta encuentra a la sociedad colombiana en un estado de fragmentación profunda de la sociedad civil, con una notoria ausencia de organizaciones sociales, exceptuando el movimiento indigena; este es el resultado de la violencia y la desesperanza, lo cual explica por qué el grado de afiliación del sector subsidiado ha sido relativamente bajo. Diferente era el panorama durante los años 70 , cuando el movimiento popular tuvo un auge significativo. Las Empresas Promotoras de Salud están autorizadas para contratar con Instituciones Prestadoras de Servicios (IPS) la atención médica, quirúrgica o científica necesaria para cubrir el Plan Obligatorio de Salud (POS), así como planes de atención complementaria. Las IPS son entidades oficiales, privadas, comunitarias o solidarias, organizadas para la prestación de los servicios de salud, dentro de las EPS - fuera de ellas. Deben prestar a los afiliados y demás beneficiarios los servicios de salud del nivel de atención corres- pondiente, de acuerdo a los parámetros legales y contractuales estipulados en los planes obligatorios o complementarios, en igual forma para todos los afiliados. Las prácticas discriminatorias están sujetas a sanciones pecuniarias; tampoco pueden impedir, restringir o interrumpir la prestación de los servicios de salud; lo cual implica la eliminación de los conflictos laborales, directamente vinculada a las nuevas formas precarias de contratación de personal.

Dado que la existencia de IPS es la garantía en última instancia de la prestación de los senvicios de salud, el Estado se compromete a fomentar su organización y sobrevivencia. Colombia ha destinado 300 mil millones de pesos para créditos en el período 1995-98, pagaderos a diez años y plazo de gracia de tres, con la finalidad de incentivar el fortalecimiento y creación de IPS, especialmente en las poblaciones con menos de 100 mil habitantes. Con este mismo objetivo, a las Empresas Promotoras de Salud que garanticen servicios en lugares apartados, les ofrecen como incentivo el pago de un $20 \%$ adicional en las tarifas de la unidad de pago por capitación. (El Tiempo, 13-05-96).

La cantidad y distribución geográfica de las instituciones Prestadoras de Servicios afecta la universalidad del sistema. A mediados de 1996, de las 10.504 IPS inscritas ante la División de Registro y Acreditación de Instituciones del Ministerio de Salud, el $80 \%$ están concentradas en grandes ciudades; el $31 \%$ en Bogotá, el $19 \%$ en Antioquia y Valle del Cauca, las dos zonas con mayor violencia; Nariño, Norte de Santander y Santander cuentan con el 4 al $5 \%$ cada uno y la 
mayoría de las intendencias sólo alcanzan al uno por mil. (El Tiempo, 13-05-96)

Legalmente las IPS tienen autonomía administrativa, técnica y financiera; sin embargo, de hecho están restringidas, por cuanto están supeditadas a la contratación por las Empresas Promotoras de Salud, mediante el sistema de pagos integrales por diagnóstico que sustituyen los pagos tradicionales por actividad o procedimiento médico. Precisamente ahí radica la razón del conflicto entre estas instituciones fundamentales del sistema de salud, ya que las EPS tienen suficiente poder para imponer el régimen tarifario, presionando la reducción de costos de funcionamiento, de modo que no excedan el valor estándar establecido. Según la Asociación Colombiana de Hospitales y Clínicas:

Si bien es cierto que la captación de dinero por parte de las EPS corresponde a una suma fija que se estipula por cada persona afiliada, la unidad de pago por capitación, que es realmente baja y no consecuente con los altos gastos derivados de la atención al paciente, las tarifas que le proponen las EPS a las IPS son exageradamente malas. Este hecho incide negativamente en el funcionamiento de las IPS, ya que la posibilidad de recuperar los costos generados por la atención y de obtener ganancias, es escasa. Las EPS están ofreciendo como modelo las tarifas del Seguro Obligatorio de Accidentes de Tránsito y del ISS, que no resultan suficientemente justas para compensar dichas actividades asistenciales $y$ comerciales. (El Tiempo, 13-05-96).
Incluso se establece legalmente la posibilidad de pagos moderadores que pueden ser aplicados por las IPS a los afiliados, para racionalizar el uso de los servicios de salud - por ejemplo, incluir un pago obligatorio a partir de la tercera consulta anual, pero tales pagos no constituyen ingresos para las IPS sino que serán recursos de las empresas promotoras de salud, aunque se prevé que el gobierno podria destinar una parte de ellos al Fondo de Solidaridad y Garantfa.

Por otra parte, las IPS carecen de adecuados sistemas de control de costos que les permitan determinar con exactitud las tarifas para comercializar sus servicios. El problema de los costos se está convirtiendo en una obsesión para los directivos de clínicas; la presión para reducir costos no está en verdad vinculada a la posibilidad de competir en el mercado, sino que puede afectar seriamente la calidad de los servicios de salud en aras de la sobrevivencia. La nueva situación en que deben funcionar las clínicas $y$ hospitales pone de relieve la importancia de las funciones administrativas $y$ ha dado lugar al surgimiento de empresas dedicadas a la asesoría y a la realización de talleres, cursos y seminarios sobre la materia.

La Ley da mucho énfasis a la competitividad, por lo cual prohíbe expresamente todos los acuerdos o convenios entre IPS, entre asociaciones o sociedades científicas y de profesionales o auxiliares del sector salud, que pretendan restringir, impedir o falsear el juego de la libre competencia dentro del mercado de servicios de salud; sin embargo no hace 
previsiones similares respecto a las EPS, las cuales están actuando en forma "solidaria" entre ellas para la fijación de las tarifas por servicios.

Por otra parte, la situación legal de las instituciones hospitalarias oficiales es un tanto diferente. La Ley 100 ordena su transformación en Empresas Sociales del Estado que deben competir con las clínicas privadas; y prevé que la prestación de servicios de salud en forma directa por la nación o por las entidades territoriales, para la ejecución del plan de atención básica, se hará principalmente a través de estas empresas sociales. Permite su asociación para la compra de insumos y servicios, para la venta de servicios de salud y para conformar entidades promotoras de salud. A fin de mejorar su capacidad de gestión para hacer frente a la competencia, se plantea el fortalecimiento de los hospitales y el saneamiento de su situación laboral: vale decir, liquidación del personal para pasar al sistema de salario integral con reducción de la nómina regular.

En cuanto a las unidades asistenciales del Seguro Social y de la Caja Nacional de Previsión, la reforma contempla la enajenación de sus activos y la realización de contratos de administración con entidades privadas, como vias para su privatización.

La dirección y control del Sistema de Salud es responsabilidad de los Ministerios de Salud y de Trabajo, espe. cialmente a través de la Superintendencia Nacional de Salud y del Consejo Nacional de Seguridad Social en Salud. Este último ejerce la dirección general, sus decisiones son obligatorias y pueden ser revisadas periódicamente; constitu- ye un órgano de concertación entre los diferentes integrantes del sistema, a saber: los Ministros de Salud, Trabajo y Hacienda y los representantes de las entidades departamentales y municipales, el Instituto de Seguros Sociales, los empleadores de las pequeñas y medianas empresas, trabajadores, pensionados, entidades promotoras de salud, instituciones prestadoras de servicios, profesionales en el área de la salud y asociaciones de usuarios. Tiene una composición múltiple, cuyo funcionamiento podria en principio parecer difícil y debería ser analizado detenidamente.

En cuanto a la Superintendencia Nacional de Salud, es el órgano de control respecto al cumplimiento de las disposiciones legales y reglamentarias; la contratación del Estado con entidades privadas y la liquidación, recaudo, giro, cobro y utilización de los recursos fiscales y rentas de cualquier origen con destino a la prestación de servicios de salud. En tal sentido están sujetas a su control las entidades promotoras de salud y similares; instituciones prestadoras de servicios, administradoras de rentas de beneficencia como loterías y juegos de azar; y las fuentes especiales de recursos fiscales, como las fábricas de licores, cervezas y sifones. La Superintendencia está facultada para amonestar e imponer multas a funcionarios y entidades incursas en irregularidades, para intervenir la gestión administrativa y/o técnica o suspender la licencia de funcionamiento. El monto de las multas oscila entre cien y mil salarios mínimos diarios para los funcionarios y hasta 10.000 para las entidades.

Puede observarse que el funciona- 
miento del sistema colombiano de salud se ha hecho descansar en los controles recíprocos de los diversos participantes, bajo los principios de calidad y competitividad, más que en el control desde el estado, aunque es indudable que éste juega un rol bien definido.

\section{Efectos Laborales de la Reforma Colombiana}

La descentralización y la privatización implican cambios en el empleo, tanto en las formas de contratación como en la cantidad de empleos y posiblemente a mediano o largo plazo, en la organización del trabajo; el gobierno colombiano ha previsto que la reforma general del sector público no afectará más de 100.000 empleos, es decir el $12.5 \%$, lo cual consideran de bajo impacto. Pero en el caso de la salud, las exigencias de reducción de costos en las instituciones prestadoras de servicios para competir o sobrevivir, también afecta drásticamente el empleo privado en salud. En ambos casos los más afectados son trabajadores con bajos niveles de calificación, lo cual podría favorecer a largo plazo la tendencia al desempleo estructural. La debilidad del movimiento laboral colombiano le ha impedido enfrentar exitosamente el proceso de reforma de la administración pública, a pesar que la mayor densidad sindical se encuentra on este sector. (Bejarano, 1993, 58-63). A medida que avanzan las reformas neoliberales en América Latina, puede afirmarse que:

En la arena política e institucional los trabajadores y sindicatos han perdido su antiguo poder de negociación; antes una fuerza cuyo respaldo era importante en las estrategias estatales de desarrollo, ahora es considerada un obstáculo para la modernización y la productividad; las conquistas laborales, antes normas ejemplares que la legislación laboral intentaba generalizar, ahora se discriminan como privilegios que hay que eliminar. La fuerza sindical en el sector público, antes una prueba del compromiso político-social, ahora parece un vicio clientelista. El movimiento obrero se estancó desde los años ochenta ... no logró defender el nivel real de los salarios y prestaciones, ni negociar o bloquear elementos estrategicos del nuevo orden institucional, como reformas laborales que eliminan prestaciones legales antiguas. (Dombois y Pries, 1993,8)

El proceso colombiano de reforma crea las condiciones para cambios profundos con el establecimiento del nuevo Código del Trabajo. "La reforma laboral de 1990 eliminó las principales barreras a la contratación laboral: desmontó la doble retroactividad de las cesantías, flexibilizó los contratos y puso fin a la estabilidad laboral forzada" (Lora, 1995,131) introduciendo el sistema de salario integral y su condicionamiento a los niveles de productividad.

Se estabiecen así las bases para formas precarias de contratación, gracias a la realización de contratos individuales con salario integral, esto es, sin prestaciones sociales; asi mismo, realizan contratos de servicios con otras empresas o con trabajadores organizados 
en cooperativas o microempresas, que desvirtúan la relación laboral convirtiéndola en un contrato entre instituciones.

Por otra parte, la intención de hacer funcionar un régimen de competencia entre las instituciones prestadoras de servicios públicas y privadas, ha puesto sobre el tapete el problema de los costos de la formación médica de pre y post-grado. Aunque hasta cierto punto los estudiantes de medicina constituyen mano de obra gratuita para los hospitales universitarios $^{2}$, se están realizando análisis que demuestran un mayor costo de atención por paciente en estos centros, explicado por cuanto se realizarian estudios en función de aprendizaje o investigación que no serian indispensables desde el punto de vista del diagnóstico.

\section{El Caos de la Salud en Venezuela}

En Venezuela la situación economica es mucho más grave que en Colombia, incluso podria hablarse de tendencias contrarias. En 1983, año en que se inicia la devaluación del bolívar, las deficiencias nutricionales no aparecian entre las cinco primeras causas de muerte, pero en 1987 ya ocupan el cuarto lugar; se ha llegado a la sítuación insólita de 800 fallecimientos anuales por hambre, sin incluir los casos no registrados; además, centenares de miles de venezolanos padecen desnutrición crónica, con sus diversas secuelas patológicas. (Maingón, 1991, 90; Fundafuturo et al, 1995, 175)

El salario mínimo vigente en 1995 , aún si se duplicara, no alcanza a cubrir el costo de la dieta de requerimientos básicos de nutrientes para mantener sana una familia de 5 personas, con riesgo para 865.000 familias cuyos ingresos están en ese orden; esto constituye un problema de inseguridad alimentaria, situación crítica si se considera la vulnerabilidad de la estrategia de suministro de alimentos, dependiente de las importaciones. (Fundafuturo et al, 1995, 175). En 1996 la situación es más grave, por la aplicación de medidas económicas drásticas que han reducido brutalmente la capacidad adquisitiva del salario e incrementado el desempleo.

Según datos de la OPS, la esperanza de vida en Venezuela $(69,7)$ era superior a la de Colombia $(68,2)$ hasta 1990 . (Maingón, 1991, 86) Es difícil suponer que esta tendencia se mantenga, pues al deterioro de las condiciones de vida, es preciso agregar la reducción sistemática del gasto en salud por habitante y la crisis de los servicios de salud. Progresivamente los problemas de salud se han incrementado en magnitud y en complejidad. Distintos grupos poblacionales en todo el país sufren enfermedades infectoconta-

2 En Colombia, los estudiantes universitarios que realizan clínicas de pre-grado cuentan con área de residencia en el mismo hospital, alimentación y una remuneración equivalente a medio salario mínimo. En forma similar los de postgrado. 
giosas, parasitosis y desnutrición, obviamente vinculadas a problemas socioeconómicos del subdesarrollo, paralelamente a enfermedades degenerativas de organos y sistemas, propias del "desarroIlo", asi como accidentes y violencias derivados de la contaminación, el trabajo inseguro y la delincuencia cada vez mayor. (Rondón Morales, 1996, 26)

\section{Estructura de los Servicios de Salud en Venezuela}

Para atender los problemas de salud, el gobierno venezolano estableció progresivamente tres modelos de atenclón en salud, similares a los existentes en Colombia antes de la reorganización total del sistema, que poseen diferencias estructurales y de funcionamiento. En general, "en Venezuela, el sector salud presenta una organización compleja... con instituciones que por desempeñar múltiples funciones, duplican sus servicios de atención. Sus numerosas instituciones y organismos públicos y privados funcionan de manera independiente, no integrados ni coordinados en una política global y específica de salud definida por el Estado". (Pérez et al, 1993,265)

a) Modelo de atención amplia, de libre acceso, financiado básicamente con recursos fiscales, ofrecido a través de más de 200 hospitales y 3600 ambulatorios, cuya infraestructura representa una de las mayores de América Latina; en 1984 tenía una capacidad de 2,7 camas por cada mil habitantes, mientras Colombia solo tenla 1,5. El sistema abierto atiende también servicios de malariología y saneamiento ambiental con programas de acueductos, cloacas y viviendas rurales. Igualmente comprende programas geriátricos y materno infantiles, especialmente los nutricionales bajo modalidades de asistencia socioeconómica. Los hospitales públicos funcionaron gratuitamente durante la primera época democrática, pero al iniciarse la crisis se fueron introduciendo modalidades de pago denominadas de "recuperación de costos"; cobran tarifas variadas en cada institución, en principio de acuerdo al estudio socioeconómico del paciente, pero sin mecanismos de control de precios ni de utilización de los recursos recaudados. Además, dentro de los hospitales se han organizado fundaciones por especialidades, especie de clínicas privadas con recursos del Estado; sobre ellas es casi imposible que las autoridades del hospital ni los directivos regionales de salud ejerzan mecanismos de control; debe reconocerse que algunas han logrado salvar el funcionamiento de ciertos departamentos. Por otra parte, los hospitales están regularmente congestionados, puesto que no se cumple la distribución de la atención médica por niveles; en el Estado Zulia, por ejemplo, los ambulatorios atienden tan solo el $38 \%$ de las consultas, cuando deberian realizar el $80 \%$.

b) Modelo de atención en salud de acceso restringido, representado por el Instituto Venezolano de Seguros Sociales, fundamentalmente dirigido a trabajadores del sector privado y más de cien modelos similares, expresados en institutos de previsión social, logrados contractualmente por los trabajadores en instituciones públicas específicas, tales como empresas del estado, ministerios, univer- 
sidades, gobernaciones, municipalidades, etc. Debido al deterioro de estos servicios, algunos sindicatos han logrado compiementarlos con la contratación de costosos seguros privados de salud, para cubrir los requerimientos de hospitalización, cirugia, maternidad, consultas de emergencia y algunas especialidades. Además, durante los últimos años se han incrementado progresivamente las empresas de medicina pre-pagada.

c) Modelo de atención privada en salud, con casi 300 clínicas pequeñas y medianas, y un número no cuantificado de consultorios de atención ambulatoria, individuales o de grupos profesionales, muchos de los cuales no están registrados a pesar de que legalmente deben someterse a la inspección y vigilancia del Ministerio de Sanidad y Asistencia Social.

Las clínicas privadas, igual que cualquier empresa venezolana, disfrutaron de las ventajas del Estado de Bienestar, especialmente por los "subsidios" otorgados bajo la modalidad de créditos con bajas tasas de interés, plazo de gracia y poca efectividad en la cobranza; gracias a la contralación de sus servicios por instituciones del Estado y por los diferentes institutos de previsión, asi como otras facilidades de acumulación de capital propias del modelo burocrático-populista. Todo ello incidió en la poca preocupación por la eficiencia, descuidando la racionalización en el uso de los recursos, tanto en lo relativo a senvicios médicos como en el manejo de la hotelería hospitalaria.

Actualmente las clínicas privadas han sido afectadas por la crisis y por las medidas económicas; según declaran directores de clínicas privadas, un buen ser- vicio médico asistencial exige hoy los mejores recursos diagnósticos y medicamentos efectivos, to cual reclama inversiones altísimas que afectan el costo de los servicios, cuya demanda ha disminuido en un $75 \%$; por ello, deben "idear fórmulas cada vez mas creativas para mantenerse competitivas en el mercado". Ante las denuncias por cobros considerados excesivos, la Asamblea Legislativa del Estado Zulia se plantea investigar los costos de la medicina privada. (Panorama, 30 y 31-05-96)

\section{Crisis de la Atención en Salud}

Los tres modelos de atención de la salud (abierto, restringido y privado) funcionaron con relativa eficacia durante la vigencia del Estado de Bienestar, gracias a la distribución de la renta petrolera y a la necesidad de legitimar el sistema democrático. El crecimiento del gasto público actuaba como mecanismo para impulsar el modelo de economía hacia adentro basado en la sustitución de importaciones, estrategia que requería garantizar la reproducción amplia de la fuerza de trabajo y la capacidad de consumo de la población.

A finales de la década del 60 y durante los años 70 , los hospitales públicos venezolanos funcionaron en condiciones óptimas. A mediados de los 70 , en momentos de estancamiento de la economia, se produce el incremento de los precios del petróleo y casi simultáneamente un proceso de endeudamiento externo sin precedentes, lo cual elevó los recursos disponibles para el gasto y la inversión, pero especialmente aceleró la corrupción generalizada, que hacía insuficiente cualquier presupuesto. 
El financiamiento del sector salud, expresado en gasto por habitante se ha ido reduciendo en forma drástica; en 1983 , año en que se evidencia el comienzo de la crisis, alcanzaba casi a $\$ 112$, disminuye a menos de la mitad, $\$ 54$ en 1988 y en 1990 se sitúa en $\$ 50,6$ (Rondón Morales, 1996,29), lo cual refleja la pérdida de la capacidad distributiva del Estado, por la disminución de la renta petrolera y por el servicio de la deuda externa. Además, influye la ineficiencia en la utilización de los recursos y la corrupción generalizada, que afectan la posibilidad de funcionamiento del modelo burocrático - populista; los efectos se aprecian en el deterioro de los servicios.

Entre los defectos de la política de gestión de hospitales, Salom Gil (1992) destaca los siguientes: Los períodos de construcción se alargan excesivamente; adquisición de equipos costosos de diferentes marcas y nacionalidades; ausencia de programas de mantenimiento de instalaciones y equipos; interferencia política de los procesos previos a la apertura; abandono de las edificaciones sustituidas por las nuevas construcciones; asignación de cargos gerenciales a personal médico no especializado en dirección de hospitales, aunque se aprovechan los avances en la formación de personal administrativo de apoyo; y finalmente, carencia de programas de supervisión y evaluación.

A mediados de 1996 los servicios de salud dependientes del Ministerio y del IVSS, prácticamente han colapsado. Con honradas excepciones, algunas basadas en interesantes experiencias autogestionarias, la mayorla de los hospitales en- frentan problemas graves de dotación de insumos y mantenimiento, que afectan seriamente sus posibilidades para funcionar; casi todos los días algún hospital es noticia, los medios de comunicación presentan imágenes deprimentes de las instalaciones y las salas de espera, deterioradas y congestionadas por los pacientes que aspiran ser atendidos, para lo cual es requisito indispensable la compra de todos los medicamentos e insumos necesarios, incluyendo guantes y otros accesorios médicos, aún en situaciones de emergencia grave. Según denuncias presentadas ante la Comisión de Salud de la Asamblea Legislativa del Estado Zulia, las Fundaciones que operan por especialidades dentro del Hospital Universitario de Maracaibo, por ejemplo, han cobrado hasta $\$ 4000$ (alrededor de dos millones de bolivares) por intervenciones de alta cirugia, a pesar que emplean infraestructura, personal e insumos suministrados por el Estado venezolano. (Panorama, 2-6-96).

A esto se deben agregar los conflictos laborales, producto del retraso en el pago de salarios, el incumplimiento de los compromisos contractuales y los bajos niveles remunerativos. A título de ejemplo vale destacar que un médico venezolano con experiencia y postgrado adscrito al Ministerio devenga un promedio mensual cercano a los $\$ 140$ y en el Instituto Venezolano de Seguros Sociales $\$ 190$, mientras que un médico colombiano en circunstancias similares obtiene cinco veces más.

El problema de personal en las instituciones públicas de salud es grave desde varios puntos de vista; por una parte, 
producto de las relaciones clientelares y de la corrupción, las nóminas han crecido en forma exagerada, especialmente en el rubro de trabajadores que no tienen relación directa con la prestación del servicio de salud; por ejemplo, en la nómina del Sistema Regional del Zulia aparece una cantidad de choferes que puede fácilmente triplicar el número de vehículos disponibles; igualmente jardineros, vigilantes, periodistas y abogados, a pesar de que no ha sido posible ganar un juicio laboral ni una reclamación a un seguro privado.

Por otra parte, además de la nómina fija existe una elevada nómina de "suplentes permanentes" muchos de los cuales contractualmente ya tienen derecho a cargo fijo. El número de trabajadores del Ministerio de Sanidad alcanzaba en 1995 los 145.000 efectivos y el $75 \%$ de los gastos del Ministerio de Sanidad y Asistencia Social -MSAS- están destinados a personal. La recurrencia permanente a créditos adicionales y la insuficiencia $y$ atraso de la contabilidad impiden tener una certeza absoluta de estos datos. La gestión de personal se agrava por la centralización y por la multiplicidad de contratos y convenios colectivos, ya que cada tipo de trabajadores tiene su propio régimen contractual, diferente para quienes pertenecen a la nómina nacional y a la del Ejecutivo regional; este caso es más grave en el Zulia, donde durante la gestión socialcristiana de Alvarez Paz se produjo un paralelismo administrativo -con secretario regional de salud y comisionado regional de salud del MSAS- to cual incrementó en cerca de 8.000 los 11.000 trabajadores que ya estaban contratados por el Ministerio, conformando un total que sobrepasa la capacidad instalada y funcional del sistema regional de salud. (Rondón Morales, 1996,97). Esta es una expresión típica de la administración pública burocrático populista, que recurre a la creación de instituciones y cargos como salida a los conflictos de poder. (Ochoa Henríquez, 1996)

Otro problema extremo es la ineficiencia del mantenimiento de la planta física y de los equipos médicos. En el reciente cambio de gestión gubernamental en el Estado Zulia, por ejemplo, al recibir las nuevas autoridades de salud la dirección de mantenimiento, se encontraron con una planta física en la cual la oficina del director posee comodidades burocráticas, pero ningún instrumento que posibilite la información y control sobre la multiplicidad de instituciones a las cuales debe atender; el taller es un depósito de chatarra donde se carece de la menor herramienta, los vehículos están abandonados en el estacionamiento, descansando sobre los rines si es que los tienen todavía, y los trabajadores, ingenieros y técnicos, pasan horas frente al edificio. En contraposición a esta nefasta experiencia, y como prueba de lo que es posible, un grupo de profesores y egresados de la Universidad Simón Bolivar han desarrollado un sistema logístico de mantenimiento para hospitales que permite actualizar, desarrollar, mejorar y perfeccionar la tecnología existente, con recursos nacionales y bajos costos, el cual ha sido ensayado exitosamente en algunos hospitales de Caracas. (Mijares, 1995)

En general, como afirma el actual 
director general del Ministerio de Sanidad y Asistencia Social, las instituciones de salud pública "se caracterizan por ser indolentes, incapacitadas, lentas y llenas de procedimientos de intervención y de control que supuestamente garantizarían una administración ajustada a una sana manera de proceder y que evitaría la corrupción, propósitos que no se lograron pero que dejaron como herencia múltiples pasos y procedimientos que son absolutamente contraproducentes ... se mantiene una planta física y servicios básicos sólo utilizados durante tres o cuatro horas al dia, una planta de personal improductiva y poco motivada y unos insumos y equipos que se deterioran voluntariamente o se sustraen, o no corresponden con las necesidades". (Rondón Morales, 1996, 33).

En el caso concreto del Instituto Venezolano de Seguros Sociales, la situación es muy grave. Sus hospitales son los que están en peores condiciones, algunos han debido suspender el funcionamiento. El Estado ha demostrado una gran incapacidad para obligar a los empleadores públicos y privados a cancelar las retenciones y aportaciones correspondientes, con márgenes de evasión anual superiores a los 60.000 millones de bolivares, por lo cual ha debido asignar regularmente recursos presupuestarios al IVSS. En este momento el Gabinete Económico recomendó la aprobación de un convenio con el Servicio Nacional Integrado de Administración Tributaria (SENIAT), institución que ha demostrado gran eficacia en la recaudación de impuestos y control de los contribuyentes, con la finalidad de que se encargue igual- mente de percibir las cotizaciones al Seguro Social antes de finalizar 1996. Igualmente se discute bien sea la posibilidad de aumentar el porcentaje contributivo, lo cual recaería sobre el sector que venía cumpliendo sus compromisos con el IVSS, o transferir los hospitales al MSAS, para dedicarse sólo a atender lo relativo a pensiones y jubilaciones, aunque los fondos correspondientes fueron desviados hacia los servicios de salud o se esfumaron gracias a la corrupción.

La transferencia de los hospitales del IVSS tiene como principal obstáculo el cumplimiento de las obligaciones laborales, especialmente lo relativo a prestaciones sociales. Solamente para liquidar todo el personal del Hospital Pedro García Clara de Ciudad Ojeda, cerrado durante un año y cuya capacidad es de 202 camas, se requieren cerca de $\$ 3.500$ millones. (Pico Méndez, 1995). Además, dado que el IVSS tiene condiciones laborales superiores a las del MSAS y las gobernaciones, en el proceso de negociación discutieron mecanismos para no desmejorar los niveles de remuneración a pesar del cambio de patrono, ya que ni el gobierno regional ni el Ministerio pueden asumir tal compromiso, to cual generaría conflictos con el personal de otras instituciones; por lo tanto, el gobierno está manejando la idea de constituir una asociación civil integrada por diversas entidades responsables de la administración. Igualmente está prevista la sustitución de parte del personal que sea liquidado, por la contratación de servicios con microempresas constituidas por ellos mismos. El retraso en las decisiones correspondientes afecta gravemente el cli- 
ma organizacional y ha sido fuente de continuos conflictos laborales.

La situación de la salud se agrava con los procesos inflacionarios, que han llevado las medicinas a precios exorbitantes, a pesar de mantenerse aún regulados; pero la cámara de productores presiona por la liberalización total de los precios. Para "resolver el problema" el Ministerio de Sanidad, las gobernaciones $y$ otras instituciones establecieron una red de farmacias sociales y populares, promocionada a página entera en varios periódicos nacionales y regionales; como prueba del posible impacto de tales farmacias, elZulia, segundo estado del país, el de mayor riesgo epidemiológico y mayor infraestructura de asistencia médica, cuenta con una sola de estas farmacias, ubicada en la capital.

Dadas las circunstancias de deterioro del sistema de salud pública, es lógico que se haya producido una tendencia progresiva hacia la privatización de los servicios de salud, como mecanismo para enfrentar los riesgos por enfermedad, este proceso se concreta en el establecimiento de sistemas tarifarios, el desarrollo de fundaciones por especialidades dentro de los hospitales -las cuales actúan como clínicas privadas- y el incremento de las instituciones de medicina pre-pagada, especialmente los seguros de hospitalización, cirugía y matemidad. Tomando como base el año 1944, se observa que para 1980 las primas de seguros medidas en miles de bolivares se incrementaron en poco mas de un $6 \%$, mientras para 1984 lo hicieron en un $15 \%$ (Maingón, 1991,94); en otras palabras, en cuatro años crecieron mas del doble que en los 36 años anteriores. Sin embargo la crisis de los seguros privados, como consecuencia de la crisis global del sistema financiero puesta al descubierto a comienzos de 1994, ha afectado las empresas de seguros, pero en los últimos años es evidente el auge de las empresas de medicina pre-pagada, incluyendo experiencias locales en los barrios. En los periódicos regionales ya han empezado a surgir preguntas sobre el funcionamiento de estas empresas y su capacidad para responder por las obligaciones asumidas, con la preocupación de que no están sujetas a ningún tipo de supervisión o fiscalización, más allá de las disposiciones del Código de Comercio. (Escalante, 1996b).

\section{Reorganización del Sistema de Salud en Venezuela}

Durante todo el período democrático, en Venezuela se han formulado propuestas de reforma de la administración pública, generalmente vinculadas a objetivos de búsqueda de eficiencia, aunque en los años 60 y 70 se justificaban por la necesidad del desarrollo y durante las dos últimas décadas se declaran propósitos democráticos. Sin embargo, la aplicación de estas propuestas se ha concentrado básicamente en las empresas del Estado vinculadas a la economia internacional y sólo recientemente en el Ministerio de Hacienda. La crisis económica, política y fiscal y las presiones de los organismos multiaterales están empujando hacia una reforma general, cuyas características fundamentales son la administración tecnocrática para la eficiencia, la privatización y como medida previa, la descentralización. (Ochoa Henríquez, 1996). Esta última sintetiza los esfuerzos 
que se han realizado hasta el momento para la modemización del sistema de salud, vinculada a la atención primaria, siendo ambas consideradas ejes estratégicos para la promoción y prevención de la salud. (Pérez et al, 1993, 306).

La descentralización afecta la división vertical del trabajo, en tanto implica transferir poder de arriba hacia abajo en la estructura decisoria y de control político y administrativo; por ello siempre está vinculada a conflictos de poder, al punto que la misma Comisión para la Reforma del Estado (COPRE) insiste en posiciones gatopardianas, según las cuales con la descentralización "el poder nacional (solo) tendrá que disminuir sus funciones de ente ejecutor y aumentar las de planificación, formulación y seguimiento de políticas, mientras que los estados y municipios deberán resaltar su papel ejecutor" (Noti-Reforma, 1996,6).

Históricamente Venezuela ha sido un país profundamente centralista, aunque su constitución la define como federalista. Los grandes conflictos post-independentistas del siglo pasado enfrentaron continuamente a los caudillos regionales con la dirigencia central y la mayor confrontación bélica la constituyó precisamente la guerra federal (1858-1863), dirigida por Ezequiel Zamora, que golpeó muy hondo el sistema político-social, pero no llegó a destruir económica ni socialmente el régimen, el cual conservaba aún rasgos oligárquicos coloniales. Su objetivo era fundar un gobierno federal, que diera al pueblo la dirección y manejo de sus propios intereses, sin sujeción a ningún otro poder, considerando al gobierno central causa fundamental de los males de la república. (Brito Figueroa, 1951; Ruiz Guevara, 1977).

La organización política federal se mantuvo hasta 1908; desde entonces se constituye la larga dictadura de J.V. Gómez, que acabó con los liderazgos regionales y provocó la constitución de un estado-nación fuertemente centralizado. La experiencia democrática hizo sus primeros intentos de 1945 a 1948 y sólo pudo establecerse sólidamente a partir de 1958, con el derrocamiento de la dictadura de Pérez Jiménez. En 1989 se inicia la profundización de la democracia con la elección directa de gobernadores $y$ alcaldes.

En lo relativo a la administración de la salud, en 1911 se crea la Oficina de Sanidad Nacional, adscrita al Ministerio del Interior y al año siguiente, la primera Ley de Sanidad, con lo cual se inició la centralización gradual del poder de decisión y de las actividades en salud, hasta entonces de carácter local; la atención, como es lógico en un país fundamentalmente rural, se concentró en la lucha contra las endemias rurales, especialmente la malaria. Desde finales de los años 30, gracias a la redistribución de la renta petrolera y a las necesidades de preservación de la fuerza de trabajo para el desarrollo capitalista, se incrementa progresivamente el gasto en salud: se inicia la instalación de una red hospitalaria nacional y el desarrollo de programas de medicina preventiva, creando para su dirección el Ministerio de Sanidad y Asistencia Social (MSAS) en 1936 y ocho años mas tarde, el Instituto Venezolano de los Seguros Sociales. La centralización se profundiza entre 1947-58, durante 
la dictadura perezjimenista, con la adscripción de los hospitales estadales y municipales al MSAS.

La democracia genera una ampliación de los servicios, especialmente en educación y salud, como estrategia consensual ante el auge de las luchas populares y por la profundización del modelo de sustitución de importaciones o de economía hacia adentro que requería la ampliación del mercado interno. A finales de la década del 70 se produce un deterioro progresivo de la situación de salud, a pesar del aumento en el gasto correspondiente y de la coyuntura favorable del incremento de los precios del petróleo, que produjo un crecimiento del PTB del $41 \%$; es el período de "la gran Venezuela" con proyectos industriales faraónicos y desborde del gasto público, del endeudamiento externo y la corrupción; en este contexto se amplía la cobertura del IVSS; se intenta agrupar en un Servicio Nacional de Salud las distintas instituciones para racionalizar el gasto; se estimula el ejercicio de la medicina privada y se simplifica la prestación del servicio con la creación de módulos en áreas marginales urbanas, profundizando la diferenciación de los servicios de salud por clases sociales. Desde la década de los 80 el país vive un proceso de recesión y ajustes económicos, se reduce sistemáticamente el gasto en salud y se inician programas focalizados hacia los sectores más vulnerables (Pérez y Jaén, 1993).

Actualmente continúan los conflictos de las regiones con el poder central, cuyas manifestaciones más evidentes se plantean en la lucha por las asignaciones presupuestarias. En 1989 se promulga la
Ley Orgánica de Descentralización, Delimitación y Transferencia de Competencias del Poder Público, que establece no solo la transferencia a las gobernaciones regionales, sino también la municipalización entre otras cuestiones de la "atención médica integral de carácter preventivo, curativo y rehabilitador", que no ha podido ejecutarse por obstáculos de diferente naturaleza, especialmente financieros y laborales. Las regiones exigen "acelerar la descentralización desmontando el centralismo agobiante y aperturando un proceso que las dote de un sistema politico democrático-participativo que supere, por necesidad del desarrollo históricosocial, a la vieja y corrupta democracia que nació en 1959" (Cabezas, 1996).

La reorganización del sistema de salud, pretende dar respuesta al compromiso de "salud para todos" suscrito hace dos décadas por todos los paises del mundo; no se ha previsto un instrumento legal específico que la operacionalice, especialmente teniendo en cuenta que la estrategia acordada consistía en la generalización de la atención primaria en salud, apelando al desarrollo de sistemas locales de salud (SILOS); esto requería poner en práctica el proceso de descentralización, pero la Ley correspondiente entró en contradicción con la Ley Orgánica del Sistema Nacional de Salud, aprobada previamente en 1988 , cuyo principio fundamental es precisamente la centralización de los servicios; esto diluyó la transferencia de competencias en una serie de alegatos jurídicos, en los cuales la mayor oposición fue ejercida por las organizaciones sindicales; finalmente condujo a salidas salomónicas de inter- 
pretación jurídica, para soslayar las contradicciones legales.

Según el actual Director General del Ministerio de Sanidad y Asistencia Social (MSAS), Roberto Rondón Morales (1996, 32-33; 169-173) el MSAS propuso una reforma de su gobierno y de su organización burocrática, cuyos rasgos básicos son los siguientes:

- Cambio de nombre a Ministerio de Salud con lo cual elimina formalmente el carácter asistencialista.

- Ampliar su intervención en el campo político, normativo y de control y descentralizar reduciendo la intervención operativa en los servicios; estos serán transferidos a los gobernadores de estado y eventual y posteriormente a los municipios; la administración de los servicios transferidos se hará mediante agencias independientes y autónomas.

- Pasar del financlamiento a la oferta al de la demanda; las organizaciones dispensadoras de servicios recibirán su presupuesto en base al número de personas atendidas o por los actos diagnósticos y terapéuticos solicitados y ofrecidos.

-Crear un Consejo Nacional de Seguridad Social y Salud, con tres grandes superintendencias: una de salud, una para enfermedades laborales y catástrofes y otra para los fondos económicos de paro forzoso, incapacidad, vejez y muerte.

-Los hospitales y otros establecimientos públicos de salud deben transformarse en Empresas Sociales del Estado para que, manteniendo su carácter público y su fin social, adquieran enfoques, procedimientos y metodologías que garanticen la eficiencia, la calidad, la productividad y la autosustentación económica, mediante el cobro de un slstema escalonado de tarifas a seguros privados, seguros de medicina pre-pagada, seguros prepagados solidarios; y un mecanismo estratificado de costos que serán subsidiados por la función de Asistencia Social de la Superintendencia de Salud.

-Reducir el $75 \%$ del personal obrero y administrativo no productor de servicios de salud- al $25 \%$.

-Establecimiento de tres sistemas seriamente competitivos con tres modelos de gestlón: modelo público abierto con sistemas de recuperación de costos, modelo de seguridad social restringido con sistema de prepago y modelo privado, los cuales deben competir entre sí financieramente y ofrecerán planes obllgatorios de salud similares para todos los venezolanos.

Como puede observarse, el trasfondo de la propuesta apunta al establecimiento de un sistema similar al de Colombia, aunque no se ha logrado estructurar en forma coherente, sobre todo considerando que se pretenden mantener los tres modelos de gestión vigentes y a pesar que en el discurso se mantenga la tesis de que los servicios no serán traspasados al sector privado.

Le ejecución de la reforma, igual que en Colombia, exige previamente la descentralización. En 1990 el MSAS firmó convenios provisionales para transferir los servicios de salud a las gobemaciones estadales, con participación del Ministerio del Interior, lógicamente atendiendo al hecho que la descentralización implica riesgo de con- 
flictos laborales, porque está ligada directamente a la necesidad de reducir la nómina estatal y facilitar la realización de transformaciones requeridas por las nuevas condiciones del estado y el modelo económico neoliberal que está impulsando, restringiendo la capacidad de respuesta sindical.

Como afirma Medellin Torres (1994, 69) tanto la descentralización como las nuevas propuestas de participación de la comunidad, tienen como objetivo subyacente "vaciar y desarticular el contenido conflictivo de los cambios profundos" que demanda la economía de mercado. Experiencias de privatización realizadas con aparatos del Estado que producen bienes o servicios para su venta en el mercado, fueron precedidas de procesos descentralizadores que impidieron a los trabajadores oponer una resistencia coherente; en el caso del Instituto Nacional de Puertos fue posible el despido de mas de 12.000 trabajadores sin ninguna reacción de peso, gracias a la desarticulación sindical producida por la descentralización y porque el Ejecutivo obtuvo crédito externo para financiar el pago de las prestaciones sociales a todos los trabajadores, incluyendo pagos cuantiosos a los dirigentes sindicales; además, éstos participaron en la elaboración del cronograma de despidos. Precisamente la mayor dificultad para ejecutar la descentralización de las instituciones de salud, radica en el establecimiento de mecanismos claros para asumir las obligaciones laborales legales o contractuales causadas y aún no pagadas; y en la existencia de los recursos financieros necesarios para responder por su pago a corto o mediano plazo. Debe aclararse que el tema de la eliminación del régimen de prestaciones sociales está sobre el tapete de la discusión en Venezuela, ligado a la propuesta de establecer un sistema amplio de seguridad social al estilo chileno o colombiano; el conflicto de intereses entre las partes ha impedido llegar a un acuerdo.

Otro obstáculo a la descentralización radica en las dificultades para asegurar las fuentes autónomas de financiamiento indispensables; en tal sentido se formalizó la creación del Fondo Intergubernamental para la Descentralización (FIDES) que no ha dispuesto de recursos suficientes; además, "el gobierno nacional, en conjunto con los gobernadores se comprometió a proponer, impulsar y apoyar las reformas legales necesarias para que los Estados puedan generar a través de impuestos estadales o sobre tasas a impuestos nacionales, ingresos propios para atender las responsabilidades de gastos derivadas de la asunción de nuevos servicios" (Sánchez Meleán, 1996,2) además de la participación en el impuesto al consumo suntuario y las ventas al mayor, así como impuestos locales al licor y a los cigarrillos. Los gobernadores de los 14 estados mineros y petroleros están presionando ante el Congreso por una Ley de Asignaciones Especiales, que incluye el financiamiento de gastos de salud $y$ asistencia social.

Pero los problemas de financiamiento también tienen causas internas al funcionamiento institucional. La ejecución de los créditos acordados con el Banco Mundial está sujeta a una serie de condiciones, tales como: a) hacer efectiva la descentralización de los centros de 
atención que serán favorecidos; b) la propiedad de los mismos debe estar en manos de los gobiernos regionales; c) ejecutar planes de formación de personal previamente aprobados por el BM; d) aprobación por el BM del plan de salud a cinco años y de los planes concretos de reestructuración de las unidades de salud; $y$ e) el financiamiento debe ser compartido, siendo el $50 \%$ responsabilidad de los gobiernos nacional y regional, cuya disponibilidad se debe garantizar previamente. Sólo aquellas regiones que han cumplido las exigencias del BM han podido empezar a ejecutar los créditos respectivos.

En los convenios provisionales de transferencia de competencias a las regiones se aclara que: a) cualquiera sea la forma organizativa que asuman los servicios públicos de salud, debe tenerse presente que el Estado, en sus diferentes ámbitos y niveles, es responsable por la efectiva vigencia del derecho constitucional a la salud, por lo cual la gobernación del Estado deberá garantizar la protección de la salud a todos los habitantes, sin discriminación de ninguna naturaleza; b) que en la gestión de los servicios públicos, especialmente en los hospitales, debe darse adecuada participación democrática a la comunidad organizada, a través de las Juntas y Comités de participación, tal como lo establece la Ley Orgánica del Sistema Nacional de Salud; $y$ c) que para asegurar la mejor eficacia en la prestación de los servicios, es conveniente ensayar nuevas formas organizativas, tales como la cogestión y autogestión (Rondón Morales, 1996, 72) aclarando que éste último concepto se ha vaciado de su contenido político, para reducirlo a la autogestión financiera exclusivamente.

Una de las dificultades para efectuar la transferencia es la gran variedad de titulares de la propiedad de las instalaciones de salud, que van desde institutos autónomos y empresas del estado ajenas al sector salud, hasta fundacio. nes, comunidades, particulares, la república, la gobernación y los municipios. Los estudios jurídicos pertinentes para establecer la titularidad, asi como las negociaciones para lograr la transferencia, también han producido un gran desgaste de recursos y energías. Tales estudios han sido costeados con recursos externos, vinculados a la posibilidad de financiamiento de proyectos de salud por el Banco Mundial, el cual ha impuesto como condición la descentralización efectiva a las gobernaciones.

Como muestra de las contradicciones internas del proceso de reforma, una de las estrategias que se ha empezado a poner en práctica es la conversión mediante decreto presidencial de algunos hospitales públicos dependientes del Ministerio de Sanidad y Asistencia Social, en servicios autónomos sin personalidad jurídica, dirigidos por una junta integrada por grupos de la sociedad civil, instituciones, empresas, gremios y autoridades regionales y locales, con atribuciones administrativas delegadas directamente del MSAS y autorización para recuperar costos. En estos casos la máxima autoridad en salud de la región puede ser simplemente un miembro más de la junta directiva y la institución queda sometida solamente a la fiscalización y evaluación por parte de la Contraloria Nacional del Minis- 
terio de Sanidad. El establecimiento de Servicios Autónomos, reduce la capacidad de influencia de las autoridades regionales de salud sobre los hospitales, lo cual ha suscitado conflictos de competencia con los directivos de tales servicios, siendo realmente un mecanismo opuesto a la descentralización. Además, después de haber decretado la creación de algunos servicios autónomos -como es el caso del Hospital Universitario de Maracaibo- se descubrió que esta figura no existe legalmente. (Navarro, 1996).

Por lo tanto, el Ministerio tiene prevista la conversión de cada hospital en una "fundación para la salud", regida por una asamblea de instituciones miembros, las cuales deben contribuir con los fondos necesarios para su funcionamiento, aunque el Ministerio continuará realizando aportes presupuestarios y ejercerá la tutela. Los estatutos previstos estipulan que los bienes serán donados a la fundación por el Ministerio o por la Gobernación, pero no plantea nada sobre la transferencia del personal que actualmente labora en los hospitales, ni acerca del régimen tarifario; solo insiste en la necesidad de controlar el costo por cada unidad, servicio o departamento, para concientizar a la ciudadanía del costo del acto médico. Se plantea además que la fundación hospitalaria podrá establecer oficinas en cualquier parte del país, aunque sin aclarar la finalidad de las mismas. (MSAS, 1996). Este sería un paso definitivo hacia la privatización.

Paralelamente al desarrollo de propuestas de reforma desde el Ministerio de Sanidad, las diversas juntas interventoras del Instituto Venezolano de los Segu- ros Sociales han formulado alternativas para su reestructuración, ya que atraviesa una grave crisis desde hace varios años, signada por deudas mil millonarias de los patronos públicos y privados y por un servicio altamente ineficaz. En este contexto, la Comisión Presidencial propone la creación de un nuevo sistema de seguridad social basado en la solidaridad contributiva y caracterizado a grandes rasgos en lo relativo a la salud, por: a) Régimen obligatorio para todos los venezolanos y extranjeros con residencia legal que trabajen bajo relación de dependencia. b) Régimen especial facultativo para amparar progresivamente a los sectores no beneficiados. c) Límite de cobertura para las enfermedades críticas o catastróficas. d) Tope máximo para las cotizaciones, de 15 salarios mínimos. e) Separación entre administración de los fondos y prestación de los servicios. (Arrieta, 1995)

Por otra parte, al menos en el Estado Zulia, se está discutiendo un proyecto de ley para regular la organización regional de la salud, la cual contempla comisiones estadales, municipales y parroquiales, para instrumentar la descentralización y juntas sociohospitalarias o sociosanitarias de hasta 15 miembros en cada hospital o ambulatorio, para ejercer la democracia participativa, con representación múltiple y funciones administrativas; dichas juntas serian presididas por un director elegido por concurso. Los establecimientos donde funcionen las juntas antes mencionadas pueden llegar a tener personería jurídica y tendrán autonomía para ejercer todas las funciones de administración de personal, adquirir bienes, contratar servicios y obtener recursos en forma autogestionaria, por 
cobro de los servicios de salud, convenios con empresas de medicina pre-pagada o alquiler de consultorios y locales. Se prevé además que la asamblea de trabajadores, denominada "consejo de consulta" debe conocer y opinar sobre el informe anual de gestión. (ALEZ, 1996). Por su parte FEDECAMARAS-ZULIA, presentó al Ministerio un proyecto similar, en el cual compartan responsabilidades el municipio y la comunidad; de hecho ya se han adelantado algunas experiencias participativas en la gestión de hospitales, en cuya directiva tienen representación las seccionales locales del organismo empresarial.

\section{Conclusiones}

La reforma del estado en Latinoamérica, y en particular la reforma administrativa, generalmente no es producto de una reflexión interna que conduzca a propuestas autónomas, acordes con las necesidades de la realidad de cada país; tanto el contenido como la forma de los cambios responden frecuentemente a imposiciones - imitaciones de modelos externos. Sin embargo, la reorganización del sistema de salud en Colombia, expresa el desafío de construir diseños propios, aun cuando se parta de modelos ajenos; indudablemente no es perfecto, pero contiene elementos que han sido mejorados progresivamente, asi como implica riesgos para los profesionales que ejercen la medicina y para los usuarios.

En nuestros paises, la reforma del sistema de salud debe dar respuesta a dos tipos de desafíos. En primer lugar, los causados por condiciones de la realidad, como son: atender el número creciente de víctimas producto de la violencia, los accidentes de tránsito y las enfermedades ocupacionales; descongestionar los hospitales fortaleciendo la atención de primer nivel; ampliar y mantener las instalaciones de salud; captar recursos financieros no estatales; asegurar la recaudación de fondos; reducir costos, especialmente los de carácter laboral $y$, con este mismo objetivo, incorporar al usuario en funciones operativas.

En segundo lugar, desde el punto de vista de los objetivos deseables, la reforma administrativa del sector salud tiene planteado el reto de conquistar niveles aceptables de salud para toda la población, en cuyo sentido debe ampliar progresivamente la cobertura y evitar la exclusión de sectores sociales y tipos de personas; además es imperativo optimizar los servicios a pesar de reducir costos, para lo cual se están manejando dos estrategias: la participación del usuario y de los profesionales de la salud en las decisiones y en el control y la modernización del modelo administrativo.

Ante estos desalíos, la organización del sistema colombiano de salud asume el reto de universalizar la cobertura del servicio, conjugando tesis neoliberales con las posiciones bismarkianas de la seguridad social clásica. Simplifica sustancialmente los procedimientos y las relaciones interinstitucionales, diluye la diferencia entre instituciones públicas y privadas de salud e impone el concepto de lo público en términos del financiamiento colectivo; modifica el criterio tradicional de asignaciones presupuestarias a cada institución para garantizar la oferta de servicios, por el financiamiento a la demanda con aportes estatales y patro- 
nales y gracias a la compensación de contribuciones de afiliados con diferentes niveles de ingresos y riesgos, incluyendo aportes patronales. A la vez, el modelo colombiano reduce el tamaño del aparato estatal responsable de la salud, minimizando la estructura y funciones del Ministerio de Salud, pero manteniendo la regulación y el control.

A diferencia del enfoque neoliberal, no es un sistema de precios, sino un sistema contributivo proporcional al ingreso individual, con beneficios acordes a las necesidades; es solidario con subsidios cruzados, integral con cobertura familiar y posee mecanismos de control para impedir las exclusiones. Difiere de la seguridad social clásica por cuanto rompe con el principio de unidad, entendida como monopolio de los sistemas de seguro y de prestación de los servicios; y crea algunos mecanismos para hacer operativo el principio de universalidad, que aunque ha aumentado significativamente (alcanza el $50 \%$ ), todavia constituye un desafío continuarla ampliando, lo cual puede implicar decisiones en diferentes ámbitos, incluyendo el fortalecimiento de las organizaciones comunitarias.

El sistema se basa en la descentralización institucional más que en la territorial y funciona con una red de instituciones públicas y privadas interrelacionadas y sometidas a la dirección del Consejo Nacional. Las empresas promotoras de salud (EPS), verdaderas compañías de seguros en este campo, deben atender un mínimo de afiliados que viabilicen la operación aprovechando las economías de escala y un máximo que garantice la competitividad, sin posibilidades de exclusión por ningún concepto; las EPS constituyen los ejes del sistema, en tanto cumplen un rol de intermediación entre las IPS, instituciones prestadoras de servicios -base del sistema- y el fondo de compensación, así como entre ambos respecto a los usuarios y sus órganos recaudadores de las contribuciones - los empleadores y las empresas solidarias de salud -. Todo el sistema está sometido a control estatal a través de la Superintendencia Nacional, con pocas posibilidades de control efectivo por parte de las entidades regionales y municipales.

El Estado garantiza la posibilidad de acumulación de capital a las EPS, las cuales concentran el mayor poder de negociación; al imponer el régimen tarifario a las clínicas y hospitales, están forzando procesos de racionalización de costos, que en cierto límite afectan la calidad de los servicios de salud y por lo tanto, colocan a las instituciones dispensadoras de servicios IPS en riesgo de demandas por mala praxis médica. Se evidencian así los límites de la eficiencia económica como criterio de gestión, especialmente desde el punto de vista de los usuarios, pero también para las instituciones más débiles del sector privado. Este es el aspecto crítico del sistema colombiano, que define el mayor reto actual y exige un profundo análisis para diseñar los correctivos necesarios.

Por otra parte, garantizar la eficiencia, ha tenido un costo para los trabajadores en cuanto a reducción de personal y al establecimiento de relaciones laborales precarias, institucionalizadas con la eliminación de las prestaciones sociales. Es indudable que tales condiciones de inestabilidad laboral debilitan cuantitativa y cuali- 
tativamente a los sindicatos $y$ afectan las condiciones de vida de los trabajadores, pero aseguran la reducción de los costos laborales, los cuales constituyen el factor más flexible en la estructura de costos; además se plantean mayores exigencias de capacitación y rendimiento.

Además, es previsible que el énfasis en la eficiencia económica afecte el rol de los hospitales públicos en el proceso de formación médica de pre y postgrado, por los elementos de costos que implica, considerando que deben competir con las clínicas privadas en la consecución de contratos de servicios con las empresas aseguradoras. De manera que la gerencia de salud y las autoridades universitarias tienen en este campo otro reto, puesto que la calidad del personal de salud está estrechamente vinculada a la conjunción de esfuerzos para garantizar la práctica que hasta ahora se ha venido desarrollando en los hospitales.

En sintesis, Colombia ha establecido un sistema de salud fundamentado en principios de mercado y de seguridad social pública, altamente regulado por el Estado pero con mínima intervención estatal directa, referida al control, ya que incluso el fondo de compensación es administrado por entidades financieras privadas. El sistema de salud colombiano se fundamenta en la seriedad y disciplina institucionales, garantizadas por algunos mecanismos de control que están funcionando con relativa eficacia.

Es obvio que la reforma del sistema de salud implica la consecución de un nuevo orden, sujeto a nuevos criterios de racionalidad técnica y política; por lo tanto, exige cambios en la división técnica y social del trabajo y en las relaciones de poder y dominación y en consecuencia, requiere redefinir principios macro-organizacionales (relativos a la red de instituciones) y micro-organizacionales, de funcionamiento interno de cada institución. Los últimos no fueron desarrollados en este documento.

Los desafíos de la reforma del sistema de salud en Venezuela son inmensos. Aún cuando no están suficientemente estructuradas ni formalizadas legalmente, las propuestas tienden a organizar los servicios intentando tomar elementos de modelos externos como el chileno y el colombiano, pero no se ha desencadenado un verdadero proceso de reflexión constructiva. La descentralización, paso previo para otras transformaciones, apenas se está iniciando, a pesar de la Ley promulgada en 1989 y de haberse firmado ya los convenios respectivos con algunas regiones. Las demás iniciativas de modernización se están produciendo en forma desarticulada y no está previsto desarrollar un sistema que integre plenamente los diversos modelos de prestación de servicios, ni existe una propuesta que apunte a ampliar sustancialmente la cobertura y calidad de los servicios de salud.

El mayor obstáculo para la aplicación inicial de los cambios propuestos -descentralización e introducción de formas intermedias de privatización - está en el actual régimen de personal, especialmente por la estabilidad laboral que implican las prestaciones sociales y por las restricciones presupuestarias para cancelar los compromisos que ellas generan. El segundo obstáculo al cambio 
parece radicar en la cultura organizacional propia de las instituciones burocrático-populistas: clientelismo, corrupción generalizada y bajo sentido de responsabilidad en amplios grupos de trabajadores, a pesar de existir ejemplos de mística profesional; los cambios culturales no exigen solamente procesos educativos, ya que las condiciones objetivas determinan cambios de comportamiento; al respecto no debe olvidarse que el Ministerio de Hacienda, a través del Servicio Nacional Integrado de Administración Tributaria . SENIAT- y su sistema de recaudación de impuestos, constituye una experiencia de modernización del estado venezolano, que está demostrando la posibilidad de funcionamiento basado en la eficiencia; próximamente será puesto al servicio de la salud, para la recaudación de las cotizaciones del IVSS.

\section{Bibliografía Citada}

puleyo Mendoza, Plinio (1990) En qué momento se jodió Colombia. Editorial Oveja Negra, Bogotá, 346 págs.

Arias, Jaime (1980). Bases Conceptuales de la Medicina pre-pagada. Modelo Kaiser de California. En Salud Pública ¿para quien? Centro de Investigación y Educación Popular (CINEP), Bogotá, 89-115.

Arrieta, José Ignacio (1995) La Seguridad Social. Reflexiones sobre las Propuestas de la Comisión Presidencial, Rev, SIC № 575, Centro Gumilla, Caracas.

Asamblea Legislativa del Estado Zulia (1996) Proyecto de Ley de Organización y Funcionamiento de los Servicios de Salud y Participación Municipal en el Estado Zulia, Comisión de Salud, ALEZ, Maracaibo.
Bejarano, Ana María (1993) Neoliberalismo y Fragmentación Política: Desafíos al Proceso de democratización en Colombla. Rev. Espacio Abierto Año 2 NN3, Maracaibo.

Brito Figueroa, Federico (1951) Ezequiel Zamora. Un Capitulo de la Historia Nacional, Editorial Avila Gráfica, Caracas.

Cabezas, Rodrigo (1996) Separatismo o Autonomía del Zulia. Panorama, 26-05-06, Maracaibo.

Castillo, Fabio (1988) Los Jinetes de la Cocalna, $5^{*}$ reimpresión. Editorial Documentos Periodísticos, Bogotá, 270 págs.

Congreso de la República de Colombia (1993) Sistema de Seguridad Social Integral, Ley 100 de 1993 y Decretos Reglamentarios, Bogotá

Diaz Callejas, Apolinar (1992) La Sinuosa Marcha de la Transición Colombiana. Rev. Nueva Sociedad N² 119, Caracas, 2835

Donahue, John D. (1991). La Decisión de Privatizar. Fines Públicos y Medios Privados. Ediciones Paidós, Barcelona, 349 págs.

Escalante, Ramón Alberto (1996a) ¿Cuáles son las Implicaciones para Venezuela de la Crisis Colombiana? Panorama, 22-04-96, Maracaibo.

Escalante, Ramón Alberto (1996b) Preguntas sobre la Medicina Pre-pagada. Panorama, 04-09-96, Maracaibo

FUNDAFUTURO, FUNDACREDESA, FUNDACION CAVENDES (1995). Un llamado de (Alertal ante la grave crisis social. Rev. Venezolana de Economía y Ciencias Sociales, $N^{*} 1$, IIES, FCES, Universidad Central de Venezuela, Caracas.

HOSPITAL ERASMO MEOZ (1989) Memoria del Primer Año de Funcionamiento. Imprenta Departamental del Norte de Santander, Cúcuta. 
Jaramillo Pérez, Iván (1994) El Futuro de la Salud en Colombia - Ley 100 de 1993 - Política Social, Mercado y Descentralización. FESCOL, Bogotá

KLisberg, Bernardo (1994) El Rediseño del estado para el Desarrollo Socioeconómico y el Cambio: Una agenda estratégica para la discusión. Rev. Reforma y Democracia, CLAD, Caracas.

Legis (1996) Cartilla Pensional y de Seguridad Social, Editorial Jurídica Legis, Bogotá.

Lora, Eduardo (1995) 25 Años de Estabilidad Salarial, Rev. Coyuntura Económica (1970-1995) Vol. XXV № 4 Fedesarrollo, Bogotá.

Maingón, Thais (1991) El Futuro de la Salud en América Latina, en Imágenes del Futuro Social de A.L. Comp. por Isabel Licha, CENDES, Universidad Central de Venezuela, Caracas.

Medellin Torres, Pedro (1994) La Modernización del Estado en América Latina: entre la reestructuración y el reformismo. Rev. Reforma y Democracia №2, CLAD, Caracas.

Mijares, Rodrigo y Lara, L. (1995) Sistema Logistico de Mantenimiento de un Hospital de Referencia Nacional, Universidad Simón Bolivar, Grupo de Bioingeniería y Biofisica Aplicada, Caracas.

Ministerio de Salud (1991) Reorganización del Sistema Nacional de Salud. Reglamentación Ley 10 de 1990. Imprenta Nacional de Colombia, 425 págs.

Ministerio de Sanidad Y Asistencia Social, Dirección General (1996) Estatutos de la Fundación para la Salud que Regirá en los Hospitales. Ministerio de Sanidad y Asistencia Social, Caracas.

Navarro, Jairo (1996) Representante de la Dirección Regional de Salud ante la Junta Reestructuradora del Hospital Pedro Garcia Clara y ante la Problemática del Seguro Social en el Estado Zulia. (entrevista)
Ochoa Henriquez, Haydée (1996). La reforma de la Administración Pública en Venezuela: Proyectos y Realidad. I Congreso Europeo de Latinoamericanistas. América Latina: Realidades y Perspectivas, Universidad de Salamanca.

Ospina Hurtado, Ximena (1996). Las Nuevas IPS. Ejes del Nuevo Sistema de Salud. El Tiempo, 13-05-96, Bogotá.

Pardo, Hernán (1994) El Sistema Privado de Previsión Social: El caso chileno. Rev. Estudios de Coyuntura № 8, IIES, Universidad del Zulia, Maracaibo, 53-70.

Pérez Itriago, Auristela y Jaén, $M^{2}$ Helena (1993) Descentralización de la Salud: Por una atención de calidad. Propuestas y escenarios. En Descentralización de la Educación, la salud y las Fronteras, Ed. Nueva Sociedad, Caracas.

Pico Méndez, Luis (1995) Hospital Pedro Garcia Clara. Reestructuración para su Transferencia al Ministerio de Sanidad y Asistencia Social. Dirección General MSAS, Caracas

Ramírez Calderón, Juan Agustin (1979) Historia del Hospital San Juan de Dios de Cúcuta. Imprenta Departamental del Norte de Santander, Cúcuta, 364 págs.

Restrepo, Guillermo (1980) Diagnóstico de la Situación de Salud en Bogotá, en Salud Pública ¿para quién?. CINEP, Bogotá, 13-38

Rondón Morales, Roberto (1996) La Descentralización de la Salud en Venezuela, Ed. Litho Color, Caracas, 219 págs.

Ruiz Guevara, J.E. (1977) Zamora en Barinas, Editorial Multicolor, Barinas

Salazar, Alonso (1990) No Nacimos pa Semilla. La Cultura de las Bandas Juveniles de Medellín. $2^{\circ}$ ed. Corporación Regional de Medellin y CINEP, Bogotá, 223 págs.

Tirado Mejía, Alvaro (1988) Introducción a la Historia Económica de Colombia. El Ancora Editores, Bogotá, 376 págs. 